\title{
A CONCORDÂNCIA VERBAL COM O PRONOME NÓS NA COMUNIDADE QUILOMBOLA SERRA DAS VIÚVAS/ ÁGUA BRANCA - AL
}

\author{
THE VERBAL AGREEMENT WITH THE PRONOUN NÓS \\ ('WE') IN THE QUILOMBOLA COMMUNITY SERRA DAS \\ VIÚVAS/ÁGUA BRANCA - AL
}

\section{Maria Helena Menezes de Souza"}

\begin{abstract}
REsumo: Nesta pesquisa investigamos a concordância verbal com o pronome nós na fala dos quilombolas, sem escolarização da comunidade Serra das Viúvas, em Água Branca -AL. Objetivamos descrever e analisar seu comportamento linguístico, tomando por base os pressupostos da Sociolinguística Variacionista (LABOV 2008[1972]). Para tratar os dados, utilizamos o programa computacional GoldVarb X (SANKOFF; TAGLIAMONTE; SMITH, 2005). Por meio deste estudo, constatamos variação na concordância verbal com o pronome nós na comunidade estudada, e que a variante preferida pelos falantes é a ocorrência de nós com verbo conjugado na terceira pessoa do singular. Os resultados também mostram que essa variação é condicionada pelas variáveis paralelismo discursivo e sexo/gênero.
\end{abstract}

Palavras-chave: Variação Linguística. Comunidade quilombola Serra das Viúvas. Concordância verbal com o pronome nós.

Aвstract: This research studies the verbal agreement with the pronoun nós ('we') in the speech of quilombolas without schooling in the Serra das Viúvas community, in Água Branca - AL. It aims to describe and analyze their linguistic behavior, based on the assumptions of Variationist Sociolinguistics (LABOV 2008 [1972 ]). To treat the data we use the computer program GoldVarb X (SANKOFF; TAGLIAMONTE; SMITH, 2005). Through this study, we found that there is variation in verbal agreement with the pronoun nós ('we') in the studied community, and that the preferred variant by speakers is nós ('we') conjugated in the third person singular. The results also show that this variation is conditioned by the discursive parallelism and sex/gender variables.

KEYwords: Linguistic variation. Serra das Viúvas Quilombola community. Verbal agreement with the pronoun nós ('we').

\footnotetext{
"Mestre em Linguística, doutoranda também em Linguística pelo Programa de Pós-Graduação em Linguística e Literatura (PPGLL) da Universidade Federal de Alagoas (UFAL), na área de concentração Teoria e Análise Linguística. E-mail: mariahelena2106@gmail.com.
} 


\section{INTRODUÇÃo}

A concordância verbal é tradicionalmente entendida como a relação de dependência entre o sujeito e o verbo em número e pessoa. No âmbito da linguística, a concordância é a conformidade morfológica entre o sintagma verbal e o sintagma nominal sujeito que implica na redundância de formas, isto é, se houver marcação de plural no sujeito, haverá marcação de plural no verbo (CASTILHO, 2010).

Ao contrário do que afirmam os manuais normativos, os estudos sociolinguísticos atestam que o sistema flexional dos verbos é variável no português brasileiro. Alguns estudos realizados no português brasileiro sobre a concordância verbal com pronome nós, citamos, Zilles, Maya e Silva (2000), Lucchesi (2006), Almeida (2006), Lucchesi et al. (2009), Santos (2013) e Silva (2018). De acordo com Zilles, Maya e Silva (2000), no português padrão, a concordância verbal em termos de desinência número-pessoal (DNP) é considerada regra categórica. No entanto, muitas são as investigações que demonstram que, nas variedades não padrão do português do Brasil, a concordância verbal precisa ser definida como regra variável.

Lucchesi (2006) aponta algumas mudanças no quadro dos pronomes pessoais do português brasileiro, estando entre elas a substituição do pronome nós pela gramaticalização da expressão nominal a gente e o enfraquecimento fonético do segmento nasal final (Eles trabaIham por Eles trabalha),o que, segundo o autor, é largamente utilizado em território nacional pelos falantes da norma popular da língua, e ainda não ganhou a competição na luta contra a variante utilizada pelos falantes da norma dita culta da língua (Eles trabalham).

Para Figueiredo Silva (1998), a morfologia específica de primeira pessoa do plural está em extinção. De acordo com a autora, as mudanças no sistema pronominal acarretam a redução do sistema de desinências verbais. Para ela, já é um fato notório que o português brasileiro está em um processo de franca perda da parte da flexão verbal relativa à desinência número-pessoal, devido à renovação no quadro pronominal promovida pela entrada de você(s), e, mais recentemente, de a gente. Segundo Lucchesi et al. (2009):

No que concerne à concordância com a $1^{\mathrm{a}}$ pessoa do plural quando esta se atualiza na forma do pronome canônico nós ou de uma categoria vazia ligada a esse pronome anaforicamente, observa-se, no português do Brasil, um quadro semelhante ao que se observa com a concordância verbal junto à $3^{a}$ pessoa do plural: uma polarização sociolinguística, calcada na alta frequência de aplicação da regra de concordância na norma culta, em contraste com uma aplicação muito baixa da regra na norma popular, a que correspondem sistemas distintos de avaliação subjetiva das variantes e tendências de mudança igualmente diferenciadas em cada uma das normas (LUCCHESI et al., 2009, p. 360). 
Além de uma frequência baixa de utilização, essa variação, de acordo com Lucchesi et al. (2009), é utilizada por falantes sem escolarização e de comunidades rurais tradicionais, principalmente comunidades quilombolas isoladas dos grandes centros urbanos. E a própria ausência de estudos sobre a variação na concordância verbal junto à $1^{a}$ pessoa do plural em materiais como do Projeto NURC, por si só, já é um indicador de que a ocorrência desse fenômeno na norma culta seria extremamente acidental ou mesmo irrelevante em termos estruturais.

Tendo em vista essa realidade, analisamos a fala dos quilombolas não escolarizados da comunidade Serra das Viúvas, situada em Água Branca no sertão do estado de Alagoas. Acreditamos que a descrição sociolinguística das variantes nós conjugado na terceira pessoa do singular (nós+3PS) e nós conjugado na primeira pessoa do plural nós+1PP explicitará e descreverá o comportamento linguístico da comunidade, uma vez que ainda não se dispõe de estudos sobre esse fenômeno.

\section{A comunidade quilombola Serra das Viúvas}

A comunidade quilombola Serra das Viúvas está situada no município de Água Branca, no interior de Alagoas, e vem se destacando ${ }^{1}$ ao longo dos anos pelo artesanato de palha de oricurizeiro e cipó, que é nacionalmente conhecido, e também por seu ponto turístico, a Pedra do Vento. Dentro da comunidade, há um coletivo chamado de Associação de Mulheres Artesãs Quilombolas Serras das viúvas, no qual fazem parte 48 mulheres residentes da comunidade, e outras que moram fora do território, mas que lá nasceram e continuam a exercer suas atividades cotidianas. Essas mulheres têm idades entre 18 e 55 anos, a maioria é casada, algumas solteiras, e outras são chefes de família. A associação, conhecida como AMAQUI, é responsável pela produção da maioria do artesanato da comunidade e, também, serve como órgão mobilizador das ações que na comunidade realizam.

A comunidade fica na zona rural do município e, assim como outros agrupamentos quilombolas de Água Branca, não é assistida pelos direitos básicos dos cidadãos, como, por exemplo, água encanada, saneamento básico, posto de saúde ou/e hospital e escola, ficando sob a responsabilidade dos quilombolas suprir essa carência. Os moradores da comunidade, em sua maioria, agricultores e artesãos, são destituídos de escolarização formal, tirando seu sustento da agricultura familiar, do artesanato e de auxílios governamentais. Na comunidade residem 86 famílias, o que corresponde a aproximadamente 250 habitantes.

A comunidade teve seu registro de remanescente de quilombo em 6 de outubro de 2009 , através da Portaria 185/200, datada de 19/11/2009. O povoado recebeu da Fundação Cultural Palmares o título de primeira comunidade quilombola da cidade de Água Branca, uma vez que, atualmente há seis do mesmo tipo no município. Desde então, os quilombolas da Serra das Viúvas, juntamente com os outros grupos de descendência afro, lutam por igualdade e equidade dentro e fora de seu território.

${ }^{1}$ Para mais informações ver: https://globoplay.globo.com/v/6550064/. Acesso em: 4 out. 2021. 


\section{Metodologia de Pesquisa}

Na composição da amostra, conforme o art. $2^{\circ}$ do Decreto $n^{\circ} 4.887$, de 20 de novembro de 2003, ${ }^{2}$ consideramos remanescentes de quilombolas todos aqueles que nasceram na comunidade quilombola Serra das Viúvas e os que moram na comunidade, mas que nasceram em outros quilombos certificados pela Fundação Palmares. Tendo em vista que a maior parte dos informantes da comunidade com idade superior a 25 anos não tem escolarização, tomamos a decisão metodológica de que participariam desta pesquisa apenas quilombolas sem nenhum grau de escolaridade; outra decisão é a de que os entrevistados não poderiam ter se afastado da comunidade por mais de dois anos seguidos.

A nossa amostra foi estratificada conforme dois grupos de fatores sexo/gênero (masculino/feminino) e faixa etária (F1-25 a 50 anos/F2-60 anos em diante). Selecionamos cinco informantes por célula e obtivemos um total de 20 informantes para serem entrevistados. $\mathrm{O}$ corpus da presente pesquisa faz parte do banco de dados do projeto "A Língua Usada no Sertão Alagoano (LUSA), " coordenado pela Profa Dra Elyne Giselle de Santana Lima Aguiar Vitório.

Em nossa pesquisa, acreditamos que diminuímos o paradoxo do observador, ${ }^{3}$ pois, como fazemos parte da comunidade, temos contato diário com os entrevistados; além disso, os quilombolas estão acostumados com gravações de entrevistas e documentários. Durante a pesquisa, não utilizamos nenhuma espécie de monitoramento linguístico, optamos por utilizar a fala cotidiana da comunidade. A participação dos informantes nas entrevistas se deu principalmente pelo fato de que o corpus levantado serviria para elaboração do trabalho de conclusão de curso da primeira quilombola a graduar-se na comunidade, ${ }^{4}$ mas também ficou acordado que esse corpus seria utilizado para outra possíveis análises.

Mesmo se reservando um momento da entrevista para explicar do que se tratava a pesquisa, poucos entendiam suas motivações, embora considerassem importante sua execução, concordaram em participar mediante assinatura do Termo de Consentimento Livre e Esclarecido.

Elaboramos uma ficha da amostra sociolinguística contendo os dados dos informantes a serem entrevistados: nome, naturalidade, sexo/gênero (Masculino/Feminino) e faixa etária (F1- 25 a 50 anos/ F2 60 anos em diante). Também elaboramos um questionário-guia de entrevistas, com tópicos de conversa, a saber:

\footnotetext{
${ }^{2} \mathrm{O}$ decreto regulamenta o procedimento para identificação, reconhecimento, delimitação, demarcação e titulação das terras ocupadas por remanescentes das comunidades dos quilombos.

${ }^{3}$ Consiste na interferência que a presença do pesquisador causa na fala do pesquisado. Durante a pesquisa, o pesquisador corre o risco de intimidar o falante pela sua presença e o estranhamento dos instrumentos eletrônicos de coleta utilizados na gravação, fazendo o falante não utilizar a fala espontânea.

${ }^{4} \mathrm{~A}$ coleta foi realizada inicialmente para o trabalho de conclusão de curso da quilombola Maria Helena Menezes de Souza. Graduação em Letras/Português na Universidade Federal de Alagoas/Campus Sertão com orientação da $\operatorname{Prof}^{\mathrm{a}} \mathrm{Dr}^{\mathrm{a}}$ Elyne Giselle de Santana Lima Aguiar Vitório.
} 
1. Fale-me sobre os aspectos da comunidade de quando você era criança.

2. Como eram as festas dos antigos casamentos?

3. Quais eram os alimentos produzidos e consumidos na comunidade?

4. O que você acha das festas culturais da comunidade?

5. E quanto à assistência médica, transporte, segurança e moradia?

6. Fale-me da sua profissão.

7. Como é o seu dia de trabalho?

8. Onde você prefere passar seus dias de lazer?

9. Fale-me de um passeio ou viagem que você fez e achou interessante.

10. Quais ações são necessárias para que a comunidade venha a alcançar seus direitos descritos no estatuto da igualdade racial? ${ }^{5}$

As entrevistas ocorreram nas residências dos quilombolas, durante o mês de março de 2016. A gravação foi feita por meio de um gravador digital e armazenamos as entrevistas no formato wav. As entrevistas duraram de 9 a 18 minutos. Tendo em vista que alguns falantes respondiam brevemente as perguntas, com o encerramento da entrevista, com poucos minutos de fala, decidimos considerar apenas as entrevistas com 9 minutos ou mais. Ao final do procedimento, gravamos 256 minutos e 44 segundos de fala, totalizando mais de 4 horas de entrevista.

Para transcrição, seguimos o Protocolo de Transcrição do Projeto "A Língua Usada em Alagoas (LUAL)", ${ }^{6}$ segundo o qual as entrevistas gravadas devem ter transcrição ortográfica. Apesar de procurarmos seguir a ortografia oficial, registramos o máximo de questões características da fala coletada, conforme podemos observar no trecho transcrito a seguir:

Nois vivia bem pruque o que pai mandava nois fazê nois fazia - nois trabaiava no alugado cum a inchadinha nas costa nois ia aculá pra aquele /Alto, Arto/trabalhá a Julia de Rita né - pá ajudá os pai da gente - ajeitá um bucado pá gente cumê - e dia de dumingo nois fazia trança fazia chapéu mãe fazia chapéu os povo tudo fraquinho $(\mathrm{L} 8 \mathrm{~F} 2 \mathrm{~F})^{7}$

Os dados foram transcritos com o auxílio do programa computacional Express Scribe, ${ }^{8}$ que está disponível gratuitamente na internet e auxilia o pesquisador na transcrição do registro de áudio.

${ }^{5}$ BRASIL, Lei 12.288/10. Estatuto da Igualdade Racial. Brasília, DF: Presidência da República, 2010. CÂMARA DOS DEPUTADOS.

${ }^{6}$ A Profa Dra Denilda Moura da Faculdade de Letras da Universidade Federal de Alagoas é responsável pelo LUAL.

${ }^{7} \mathrm{~A}$ identificação de cada falante se deu pela letra L, seguida no número da transcrição. O sexo/gênero feminino foi representado por $\mathrm{F}$ e masculino por M. Para falantes de 25 a 50 anos, utilizamos F1, para falantes de 60 anos em diante, F2. ${ }^{8}$ Disponível em: : http://www.baixaki.com.br/download/express-scribe.htm. Acesso em: 4 out. 2021. 


\section{A VARIÁVEL DEPENDENTE}

A concordância verbal com a primeira pessoa do plural no português brasileiro é um fenômeno variável, que tem despertado o interesse de vários pesquisadores que investigam o assunto. Uma vez considerada regra categórica, os estudos na área da Sociolinguística Variacionista atestam a existência de duas formas concorrentes para representar a realização da concordância verbal com a primeira pessoa do plural, a saber, nós conjugado com a terceira pessoa do singular (nós+3PS), como no exemplo (1), e nós conjugado com a primeira pessoa do plural (nós+1PP), conforme o exemplo (2).

1. E quando nós chegava pá jantar jantava coméra/ como era que nós jantava inhame uns inhames do mato era isso que nós jantava (L2OF2F)

2. Nós não podemos fazê isso - $\varnothing$ podemos? (LiıFIIM)

Segundo os resultados da análise, os falantes da comunidade quilombola Serra das Viúvas têm um comportamento linguístico variável no que se refere à aplicação da concordância verbal com a primeira pessoa do plural. O programa Goldvarb X mostrou que houve 184 ocorrências do fenômeno, e, enquanto 132 foram de nós+3PS, o que representa $72 \%$ dos dados, apenas 52 realizações foram de nós $+1 P P$, o que representa $28 \%$ dos dados. Nota-se, assim, a preferência linguística da comunidade pela ausência de concordância verbal, isto é, favorece-se a variante nós+3PS.

De acordo com Lucchesi et al. (2009), o cenário de um elevado grau de aplicação da regra de concordância muda significativamente quando se passa a observar a periferia dos centros urbanos, falantes com pouca ou nenhuma escolaridade e comunidades rurais e isoladas. Bortoni-Ricardo (1985) também comunga das mesmas ideias, pois relata que a norma dos falantes com pouca ou nenhuma escolaridade se caracteriza exatamente pelo reduzido uso de desinências verbais de número e pessoa. Essas características citadas pelos autores podem ser constatadas na comunidade de fala aqui estudada, já que se situa numa região interiorana do sertão de Alagoas, e, além disso, a pesquisa foi realizada entre falantes não escolarizados.

Os resultados apresentados nesta pesquisa também são comparáveis aos de Souza (2021), que, analisando a fala da mesma comunidade com o fenômeno de concordância verbal de terceira pessoa do plural, obteve um percentual de $75 \%$ de ausência de concordância verbal, e apenas $25 \%$ de presença de concordância verbal. Os resultados dessas pesquisas mostram que a ausência de concordância verbal pode ser uma característica própria da fala da comunidade quilombola Serra das Viúvas, assim como é para tantas outras comunidades interioranas, como apontam Lucchesi et al. (2009). 
É importante ressaltar que outros fatores concorrem para a ausência de uso da concordância verbal com $\mathrm{P} 4,{ }^{9}$ como, por exemplo, o crescente uso de a gente em lugar de nós, cuja utilização exige sempre o verbo na terceira pessoa do singular; nesse caso, é possível pensar em progressiva redução de uso da concordância. De acordo com os resultados de Souza (2020), os falantes não escolarizados da comunidade quilombola Serra das Viúvas têm preferência pela variante a gente ao invés de nós para ocupar a posição de sujeito de primeira pessoa do plural, resultados que podem também influenciar a utilização da concordância verbal de nós+3ps dentro da comunidade.

De acordo com Bortoni-Ricardo (1985), o sufixo de primeira pessoa do plural (mos), que muitas vezes é oralizado como (mus), na língua padrão, pode se realizar como ( $\mathrm{mu}$ ) ou ser simplesmente apagado, e, no dialeto caipira, a variante $(\mathrm{mu})$ geralmente coocorre com uma mudança da vogal temática $(/ \mathrm{a} />/ \mathrm{e} /)$ nos pretéritos da primeira conjugação, como em nós falamos versus nós falemu. Tendo em vista essa reflexão, e considerando também a proposta de pesquisadores como Lucchesi et al. (2009) e Silva (2018), que enfatizam a realização da concordância de $\mathrm{P} 4$ com os alomorfes (mo), (emo) e (imo), como nos exemplos (3) e (4), resolvemos testar a frequência dessas realizações na comunidade Quilombola Serra das Viúvas. Para isso, realizamos uma rodada à parte no programa GoldVarb X.

3. Mãe tirou pra Delmiro e nós subimo e cá eles forum arrancar mandioca (LiFiF)

4. Não nós passemo na selva lá tem uma floresta né (L5FiM)

De acordo com os resultados obtidos, verificamos uma frequência de $7 \%$ para (mos), $11 \%$ para (mo), $10 \%$ para (emo), $0 \%$ para imo e $72 \%$ para o morfema (zero). Sendo assim, a partir dessa divisão, podemos perceber que os índices de menor realização estão em (mos); em seguida, observamos (emo), com um percentual de 10\%. É interessante observar que, na comunidade de fala analisada, não houve nenhuma realização do alomorfe (imo). As realizações de (mo) depois das realizações do morfema zero, foram as mais utilizadas, no entanto, com percentual mínimo, sendo $11 \%$. Os maiores índices de aplicação estão de fato no morfema zero, que foi a variante que se destacou nos percentuais gerais do estudo.

\section{VARIÁVEIS ESTATISTICAMENTE SIGNIFICATIVAS}

Partindo do resultado de 72\% de aplicação de nós $+3 P S$ na comunidade quilombola Serra das Viúvas, apresentamos, a seguir, os grupos de fatores linguísticos e sociais que condicionam a realização do fenômeno. Os grupos de fatores selecionados para este estudo foram sete, a saber: saliência fônica, posição do sujeito, elementos intervenientes entre sujeito e verbo, explicitação do sujeito, paralelismo discursivo, sexo/gênero e faixa etária. Desses, apenas dois foram selecionados como estatisticamente significativos: o paralelismo discursivo e o sexo/gênero.

${ }^{9}$ Concordância verbal com a primeira pessoa do plural. 


\section{Paralelismo discursivo}

Segundo o princípio do paralelismo discursivo, aplicação de uma determinada marca tende a levar a utilização da mesma consecutivas vezes em uma sentença. Para Scherre (1998), a repetição das variantes de uma mesma variável dependente no discurso tem se evidenciado como uma restrição importante na análise de fenômenos variáveis de todos os subsistemas linguísticos em diversas línguas, podendo ocorrer entre as cláusulas (plano discursivo), no interior da oração (plano oracional), no interior do sintagma (plano sintagmático) e entre palavras e no interior da palavra (plano da palavra). Segundo Lucchesi et al. (2009), em uma cadeia de orações com referência ao mesmo sujeito, se o falante utiliza o morfema verbal de número e pessoa na primeira oração, ele tende a utilizar esse morfema nas orações seguintes. Com base nesse princípio, essa variável foi estruturada da seguinte maneira: realização verbal isolada como em (5), primeira referência verbal, como em (6), realização verbal antecedida por nós em concordância com a terceira pessoa do singular, como em (7), e realização verbal antecedida por nós em concordância com a primeira pessoa do plural, como em (8).

5. Nois butava iágua (LiFIF)

6. A:i quando era bem cedinho nós se atirava nós tudo pra nós ajudar levar (LiFIF)

7. Ah o que nois temos que fazê pá $\emptyset$ alcançá isso é nois se reuní todo mundo junto - e $\emptyset$ falá com um guverno assim um guvernadô ou um é um guvernador (L3FIF)

8. A gente se reuni quando acabá $\emptyset$ vamu na casa de todas as pessoa e cada uma pessoa da um prato de cumida e nois faz a festa junto todo mundo junto- (L3FIF)

Vejamos os resultados na tabela 1:

Tabela 1 - Concordância verbal com $\mathrm{P} 4$ de acordo com o paralelismo discursivo

\begin{tabular}{c|ccccc|cccc}
\hline Paralelismo Discursivo & \multicolumn{4}{|c|}{ Nós+3PS } & \multicolumn{4}{c}{ Nós+1PP } \\
\hline & Aplic. & Total & Perc. & PR & Aplic. & Total & Perc. & PR \\
\hline Realização isolada & 35 & 51 & $68 \%$ & .44 & 16 & 51 & $31 \%$ & .56 \\
\hline Primeira referência verbal & 39 & 50 & $73 \%$ & .50 & 11 & 50 & $27 \%$ & .50 \\
\hline Antecedida pela 1PP & 8 & 24 & $33 \%$ & .14 & 16 & 24 & $67 \%$ & .86 \\
\hline Antecedida pela 3PS & 59 & 68 & $87 \%$ & .68 & 9 & 68 & $13 \%$ & .32 \\
\hline
\end{tabular}

Fonte: Elaboração própria (2021)

Conforme os resultados da tabela 1, houve predominância da aplicação da variante nós+3PS na comunidade quilombola Serra das Viúvas quando antecedida pela referência verbal de $3 P S$, com 59 realizações, um percentual de $87 \%$ e peso relativo .68, em ocorrências como (9) e (10), o que comprova o princípio do paralelismo discursivo, de que uma marca verbal leva à outra. Na aplicação da variante nós+1PP, podemos depreender que o fator referência verbal 
antecedida pela $1 P P$ foi o que mais favoreceu a variante padrão, com 16 aplicações, um percentual de $67 \%$ e peso relativo .86 , comprovando pela segunda vez o princípio do paralelismo discursivo, em ocorrências como (11) e (12). O segundo fator que se destacou como relevante para esta variante foi realização verbal isolada, com 16 realizações, um percentual de $31 \% \mathrm{e}$ peso relativo $.56 \mathrm{em}$ casos como (13) e (14).

9. Nois vivia bem pruque o que pai mandava nois fazê nois fazia - nois trabaiava no alugado cum a inchadinha nas costa nois ia aculá pra aquele /Alto, Arto/trabalhá a Julia de Rita né - pá ajudá os pai da gente - ajeitá um bucado pá gente cumê - e dia de dumingo nois fazia trança $\emptyset$ fazia chapéu mãe fazia chapéu os povo tudo fraquinho (L8F2F)

10. Só num comprava a água e a lenha porque nós botava- nós se ajuntava aquele bututão e Ø ia pegá (L14F2F)

11. Teve um ano mermo que nós trabaiemo tanto no alugado - nós - só na roça dos otro por conta nós cavemo doze mil cova de mandioca e $\emptyset$ cavemo nove em nossa roça (L1OF2M)

12. Que que nós podemos fazê - nós fraco não podemos fazê nada (L11F2M)

13.E nós nunca fumos numa escola minha fia (L15F2F)

14. Nós num somos parente (L16F2M)

Lucchesi et al. (2009), que também analisaram a fala de três comunidades quilombolas de regiões interioranas da Bahia, observaram um comportamento parecido no que diz respeito à variação da concordância verbal com P4; nessa pesquisa, o paralelismo discursivo foi considerado uma variável estatisticamente significativa, conforme os seus resultados, a presença de uma forma verbal marcada na oração anterior foi o fator que mais favoreceu a aplicação da regra de concordância verbal, com uma frequência de $48 \%$ e peso relativo de .72 . Semelhante ao estudo dos autores, em nossa pesquisa, observamos que os grupos de fatores com maior relevância para a variável foram os que tinham em sua anteposição uma forma verbal marcada, seja ela de $3 P S$ ou $1 P P$, ambos os fatores condicionam a aplicação das duas variantes analisadas.

\section{SEXo/GÊNERO}

Almeida (2006), que analisou a fala da comunidade quilombola São Miguel dos Pretos, em Restinga Seca/RS, constatou que, em todas as suas rodadas, as mulheres estão à frente dos homens ao empregarem um índice maior de concordância verbal com P4. No nosso estudo, a variável sexo/gênero foi dividida nos fatores masculino e feminino. Vejamos o que nos mostra a ilustração dos resultados dados pelo GoldVarb X na tabela 2: 
Tabela 2: Resultado da aplicação de concordância verbal com P4 de acordo com o sexo/gênero

\begin{tabular}{c|cccc|ccccc}
\hline \multirow{2}{*}{ Sexo/gênero } & \multicolumn{4}{|c|}{ Nós+3PS } & \multicolumn{5}{c}{ Nós+1PP } \\
& Aplic. Total & Perc. & PR & Aplic. & Total & Perc. & PR \\
\hline Feminino & 98 & 126 & $78 \%$ & .57 & 28 & 126 & $22 \%$ & .43 \\
\hline Masculino & 34 & 58 & $59 \%$ & .34 & 24 & 58 & $41 \%$ & .66 \\
\hline
\end{tabular}

Elaboração própria (2021)

Os resultados mostram que as mulheres quilombolas preferem a utilização de nós+3PS, pois esse fator se mostrou relevante na aplicação da referida variante, com 98 ocorrências, um percentual de $78 \%$ e peso relativo .57. Podemos observar também que os homens preferem utilizar a variante padrão, pois tal fator se mostrou relevante, com 24 casos, um percentual de $41 \%$ e peso relativo .66. Esses resultados se contrapõem aos de Almeida (2006) e Carmo (2016), haja vista que, nas duas pesquisas, as mulheres se apresentam com os maiores índices de aplicação da variante padrão, e os homens são observados como inovadores e mais adeptos da utilização de nós+3PS.

Para verificar a atuação da variável sexo/gênero, realizamos o cruzamento dessa variável com faixa etária. Mesmo a variável faixa etária não sendo apontada como estatisticamente significativa neste estudo, consideramos importante observar sua atuação em contraste com o sexo/gênero.

Gráfico 1 - Resultado da aplicação de nós+3PS de acordo com sexo/gênero e faixa etária

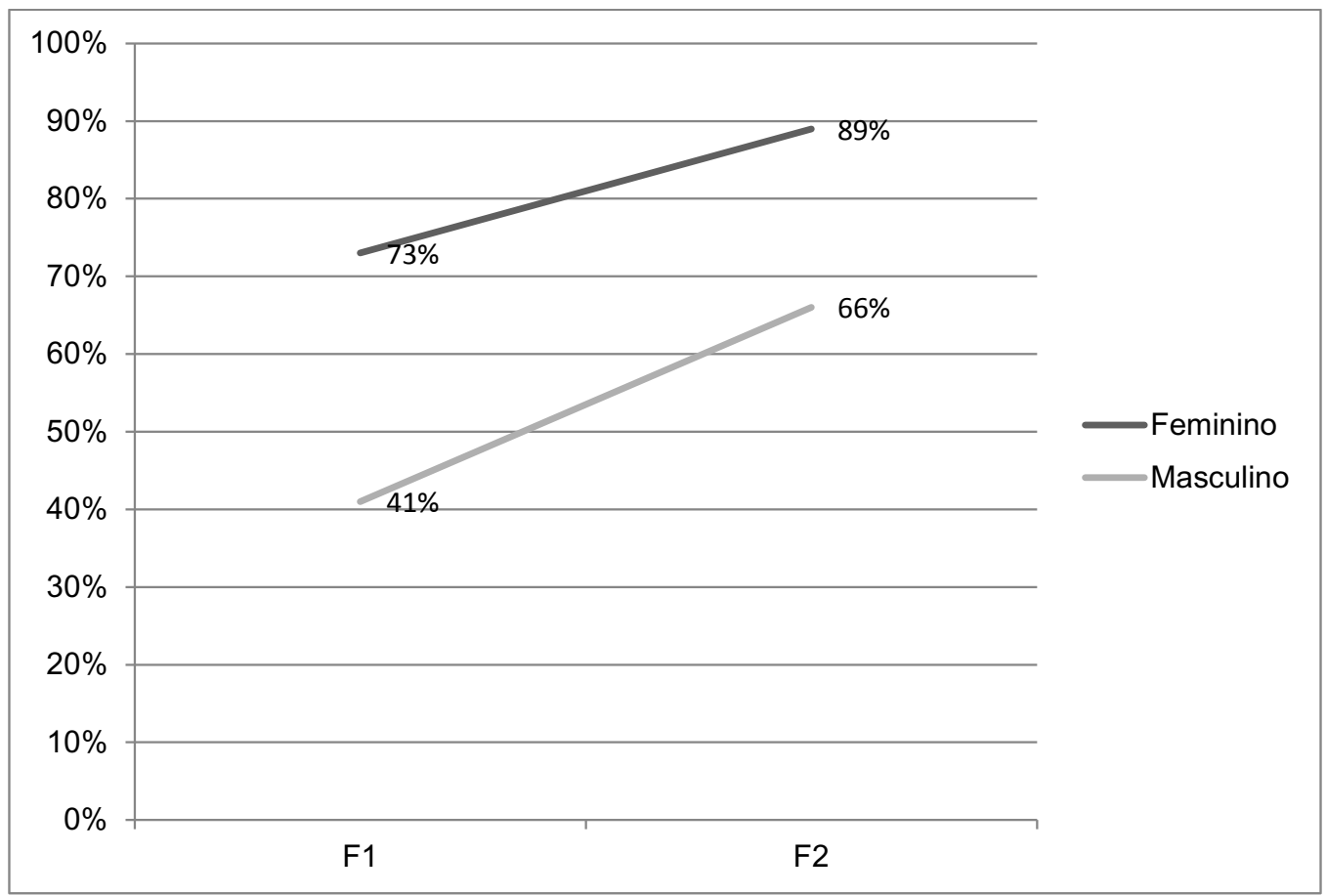

Fonte: Elaboração própria (2021) 
De acordo com o gráfico 1, verificamos que a variante nós + 3PS é a forma preferida entre as mulheres, tanto da faixa etária F1 (25-50 anos) quanto da faixa etária F2 (60 anos em diante), a faixa mais nova com um percentual de $73 \%$, e a idosa com $89 \%$. Observamos também que os homens da faixa etária F2 chegam a ser mais adeptos da variante nós+3PS do que os homens da faixa etária F1, com um percentual de 66\%.

Os homens da faixa $\mathrm{F} 1$ foram os que se destacaram como os que mais utilizam a variante padrão, apresentando um percentual de frequência de $41 \%$ de nós $+3 P S$. Esse grupo se destaca como o mais conservador da comunidade. Sendo assim, podemos concluir que as mulheres da faixa etária F2 são as que apresentam o comportamento linguístico mais inovador, e os homens adultos são os mais conservadores dentro da comunidade quilombola Serra das Viúvas.

\section{VARIÁVEIS ESTATISTICAMENTE NÃO SIGNIFICATIVAS}

Dos sete grupos de fatores controlados nesta pesquisa para as variantes nós+3PS e nós+1PP, quatro foram considerados estatisticamente não significativos pelo programa computacional GoldVarb X: a saber, explicitação do sujeito, posição do sujeito, elementos intervenientes entre sujeito e verbo e faixa etária, por ordem de eliminação. No entanto, esses fatores são importantes para as análises de fenômenos variáveis nas pesquisas que seguem as vertentes da Sociolinguística Variacionista, principalmente nos estudos que analisam a variação nós+3PS e nós+1PP.

\section{Conclusão}

Nesta pesquisa, analisamos o comportamento linguístico dos falantes não escolarizados da comunidade quilombola Serra das Viúvas em relação ao fenômeno da concordância verbal com $\mathrm{P}_{4} \mathrm{e}$, a partir dos resultados, constatamos variação na concordância verbal com o pronome nós na referida comunidade. Além disso observamos que os falantes optam preferencialmente pela utilização de nós+3PS, com um percentual de $72 \%$ de aplicação. Realizamos ainda uma rodada à parte, para verificarmos a utilização dos alomorfes nessa variação, e, de acordo com os dados, a preferência dos falantes é pela posição vazia. No entanto, constatamos a atuação do alomorfe (mo) que concorre com o (mos) com um percentual de $11 \%$, (mos) apresentou apenas $6 \%$ de aplicação e o alomorfe (emo) apareceu com um percentual de 10\%. Do alomorfe (imo) não houve ocorrências.

De acordo com os resultados, os contextos que mais influenciam nós+3PS, são paralelismo discursivo e sexo/gênero, sendo que os fatores que mais propiciam as ocorrências de nós+3PS são realizações verbais antecedidas pela 3PS e sexo/gênero feminino. Nas variáveis estatisticamente não significativas, constatamos que foram quatro: explicitude do sujeito, posição do 
sujeito, elementos intervenientes e faixa etária. Essas variáveis não foram consideradas com influentes na variação em estudo.

Assim como a pesquisa de Zilles, Maya e Silva (2000), Lucchesi (2006), Almeida (2006), Lucchesi, (2009), Carmo (2016) e Silva (2018), os nossos resultados atestam a variabilidade do fenômeno de concordância verbal com $\mathrm{P} 4$, e evidencia o fato de que o português brasileiro é linguisticamente diversificado, marcado por diferenças e semelhanças influenciadas por questões de ordens sociais e linguísticas. As comunidades tradicionais e rurais costumam apresentar maior índice de variabilidade em concordância verbal, e, quando estendemos essa discussão para a fala das pessoas sem escolarização, percebemos cenário semelhante. A variação linguística é uma constante em todas as línguas naturais, e não deve ser encarada como ruim ou maléfica para as línguas, mas aspecto natural da linguagem, característica que a faz provida de beleza singular.

Por fim, consideramos de suma importância a expansão das pesquisas dos fenômenos linguísticos variáveis nas diferentes comunidades de fala, pois, assim, teremos um panorama dos falares brasileiros. Ressaltamos também a necessidade de tais fenômenos serem mais bem explorados e apresentados socialmente, de forma que deixem a posição de regra categórica e assumam a posição de regra variável.

\section{REFERÊNCIAS}

ALMEIDA, A. P. A concordância verbal na comunidade de São Miguel dos Pretos, Restinga Seca, RS. 2006. 159 f. Dissertação (Mestrado em Linguística) - Instituto de Letras, Pós-Graduação em Letras, Universidade do Rio Grande do Sul. Porto Alegre, 2006. Disponível em: https://lume. ufrgs.br/bitstream/handle/10183/7627/000549864.pdf?sequence=1\&isAllowed=y. Acesso em 4 out. 2021.

BORTONI-RICARDO, S. M. A urbanização dos falantes do dialeto rural. Um estudo sociolinguístico no Brasil. Cambridge: Cambridge University Press, 1985.

CARMO, S. D. S. A variação na concordância verbal com a primeira pessoa do plural em comunidades rurais do semiárido baiano. 2016.163 f. Dissertação (Mestrado acadêmico em Estudos Linguísticos) - Universidade Estadual de Feira de Santana, Feira de Santana, 2016.

CASTIlHO, A. T. de. Nova Gramática do Português Brasileiro. São Paulo: Contexto, 2010.

GUY, G.; ZILLES, A. Sociolinguística quantitativa: instrumental de análise. São Paulo: Parábola, 2007.

LABOV, W. Padrões sociolinguísticos. São Paulo: Parábola, 2008. 
LUCCHESI, D. Parâmetros sociolinguísticos do português brasileiro. Revista ABRALIN. V.5, n 1/2006. p. 84-112 Disponível em: http://www.abralin.org/revista/RV5N1_2/RV5N1_2_art4.pdf. Acesso em: 3 jun. 2020.

LUCCHESI, D.; BAXTER, A.; SILVA, J. A. A. A concordância verbal. In: LUCCHESI, D., BAXTER, A.; RIBEIRO, I. (Org.). O português afro-brasileiro. Salvador: EDUFBA, 2009, pp. 331-371. ISBN 97885-232-0875-2. Available from SciELO Books http://books.scielo.org. Acesso em: 20 jul. 2020.

SANKOFF, D.; TAGLIAMONTE, S.; SMITH, E. GoldvarbX: a variable rule application for Macintosh and Windows. Department of Linguistics, University of Toronto, 2005.

SANTOS, D. A concordância verbal na fala de afrodescendentes da comunidade quilombola Muquém, União dos Palmares - Alagoas. Maceió: UFAL. 2013.125 f. Dissertação (Mestrado em Linguística) - Faculdade de Letras, Universidade Federal de Alagoas, Maceió, 2013.

SCHERRE, M. M. P. Paralelismo Linguístico. Universidade Federal do Rio de Janeiro. Rev. Est. Ling., Belo Horizonte, v.7, n.2, p.29-59, jul./dez. 1998.

SILVA, M. C. F. Inovações morfológicas no português brasileiro. In: CABRAL, L. G.; GORSKI, E. (Org.) Linguística e Ensino: Reflexões para a prática pedagógica da língua materna. Florianópolis, Insular, p.181-198, 1998.

SILVA, J. A. A concordância verbal com o pronome nós no Sertão alagoano. Delmiro Gouveia: UFAL Licenciatura em Letras. Campus Sertão. Universidade Federal de Alagoas, 2018.

SILVA. J. A.; VITÓRIO. E. G. S. L. A. A concordância verbal com o pronome nós no Sertão alagoano. Revista Porto das Letras, v. 6, n. 1. p. 50-73. 2020.

SOUZA, M. H. M. A concordância verbal de terceira pessoa do plural na fala da comunidade quilombola Serra das Viúvas/ Água branca - AL. Web Revista SOCIODIALETO, [S.l.], v. 11, n. 33, p. 1-22, jun. 2021. ISSN 2178-1486. Disponível em: http://sociodialeto.com.br/index.php/ sociodialeto/article/view/366. Acesso em: 4 out. 2021.

SOUZA, M. H. M. A variação nós e a gente na posição de sujeito na comunidade quilombola Serra das Viúvas/Água Branca-AL. 2020.93 f. Dissertação (Mestrado em Linguística) Faculdade de Letras, Programa de Pós-Graduação em Linguística e Literatura, Universidade Federal de Alagoas, Maceió, 2020.

ZILLES, A.M.S.; MAYA, L., SILVA, K. A concordância verbal coma primeira pessoa do plural em Panambi e Porto Alegre, RS. Organon. v. 42, n. 2, p. 27/44. 2007.

Recebido para publicação em: 16 abr. 2021. Aceito para publicação em: 23 ago. 2021. 